\title{
Self-esteem, propensity for sensation seeking, and risk behaviour among adults with tattoos and piercings
}

\author{
Bo-Kyung Hong, Hyo Young Lee \\ Department of Beauty, Kyungil University; Department of Health Administration, Dongseo \\ University, South Korea
}

\section{Significance for public health}

The age range and occupations of people who undergo tattoo procedures have diversified with their increasing popularity as cosmetic procedures. This study investigated general characteristics of adults with tattoos and piercings and determined relationships between these body cosmetic procedures and self-esteem, sensation seeking, and risk behaviour. This study provides useful information as to whether adults with tattoos and piercings might be appropriate target groups for public health education, and further identifies factors associated with adults who choose to have tattoos and piercings.

\footnotetext{
Abstract

Background: In recent years, increasing numbers of adults and adolescents have opted to undergo tattoo and piercing procedures. Studies among adolescents with tattoo and piercing have usually explored the relationship between one factor and the decision to have tattoos and/or piercings. The aim of this study was to determine relationships between body cosmetic procedures and selfesteem, propensity for sensation seeking, and risk behaviours among adults.

Materials and Methods: The subjects were divided into two groups, i.e., those with $(\mathrm{n}=429)$ and those without tattoos/piercings $(n=237)$, and self-esteem, propensity for sensation seeking, and risk behaviour were compared between the two groups using self-report questionnaires. To analyse differences in self-esteem and the propensity for sensation seeking, general characteristics were statistically adjusted. In addition, general characteristics, self-esteem, and propensity for sensation seeking were statistically adjusted to determine differences in the propensity for risk behaviour between the two groups.

Results: Significant differences were observed in age, marital status, income level, occupation, values or sensitivity to fashion, and educational level between the group with and that without tattoos/piercings. There was no significant difference in self-esteem, whereas there were significant differences in the propensity for sensation seeking and risk behaviour between the two groups.

Conclusions: Continuous attention to, and interest in, the increased incidence of tattooing and piercing are necessary, especially in terms of public interventions for health education and health promotion, as these forms of self-adornment are associated with behaviours that pose a risk to health.
}

\section{Introduction}

Tattooing and piercing are invasive procedures that lead to permanent modification of the body. Generally, tattooing involves invasive surgical procedures to create decorative designs using multiple needles with indelible dye injections into the skin, ${ }^{1}$ and piercing involves penetration of the body using jewellery, such as in the eyebrows, ears, lips, tongue, nose, and navel. ${ }^{2}$

Historically, tattooing gained popularity with various social movements in the early $1950 \mathrm{~s}$, when body cosmetics came into widespread use. ${ }^{3}$ In the past, tattoos were often regarded as a source of social stigma [defined as disapproval and discrimination toward an individual or group displaying undesirable deviant individuality, which results in anxiety, discrimination, or exclusion], because they were common among people who engaged in deviant behaviour. ${ }^{4,5}$ Accordingly, negative connotations were ascribed to people with tattoos, such as their being deviants, drug abusers, or rebellious students lacking in religious morality. ${ }^{6-8}$ Furthermore, tattooing was often regarded as an irresponsible act connected with impulsivity. ${ }^{9}$

In recent years, the number of people undergoing tattoo procedures has rapidly increased, the association of tattoos with negative symbolism has changed, and tattoos have become more accepted as a form of physical and cultural expression; they are accepted as a means of expressing individuality or fashion, and celebrities have helped to turn tattoos into a mode of expression of the popular arts. Additionally, the age range and occupations of people who undergo tattoo procedures have diversified with their increasing popularity as a cosmetic procedure. ${ }^{5,10}$ Therefore, studies need to identify factors related to tattooing and piercing among different age groups. Low self-esteem is related to health-compromising behaviours, such as eating problems, early sexual activity, substance use, suicidal ideation, and psychological factors such as depression and stress. ${ }^{11,12}$ Thus, researchers have emphasised the relationship between self-esteem and health behaviours/psychological factors. A high propensity for sensation seeking is closely related to psychological problems, gambling, and risky sexual behaviour. ${ }^{13-15}$ The propensity for risky behaviour has often been used to mean the same as engaging in risk-taking behaviour. ${ }^{16,17}$ Thus, subjects with tattoos and/or piercings could be a vulnerable group requiring a health awareness program or public health education.

There have been numerous studies on cosmetic procedures including tattooing and piercing. Until the 1990s, studies were mainly performed on tattoo- and piercing-related diseases such as hepatitis B and C, infections, and allergic reactions. ${ }^{18,19}$ However, since the 2000s, studies have covered a wide range of topics, 
including quality of life, risk behaviour, sensation seeking, deviant behaviour in teenagers, poor mental health, and psychological factors. ${ }^{20,21}$ Tattooing and piercing were reported to be closely linked to these factors and to be related to smoking, alcohol consumption, and suicidal thoughts. ${ }^{22-24}$ However, those studies focused only on teenagers or university students, and there have been few studies on the general adult population. Furthermore, various factors related to tattoos and piercings have been studied separately, ${ }^{20-24}$ making it impossible to understand relationships among the major related factors and which of these were influential after controlling for the influences of others.

The present study investigated general characteristics in adults with tattoos and piercings and explored relationships between these body cosmetic procedures and self-esteem, sensation seeking, and risk behaviour to determine the implications for public health, especially among adults.

\section{Materials and Methods}

\section{Study population}

This was an analytic cross-sectional study. Two study groups of Korean adults aged from their 20s through to their 50s were selected: those with tattoos/piercings and those without tattoos or piercings. In general, tattoos only included permanent body cosmetic procedures and excluded temporary tattoos such as henna tattoos and semi-permanent make-up tattoos. In addition, piercing excluded the case of single piercings in each ear for typical earrings. Subjects in the control group had no tattoos or piercings.

\section{Data collection}

Data were collected by an experienced researcher using an online community panel survey with a snowball sampling method, and an off-line survey that used random sampling. The online community panel survey was given to people registered in a tattooing and piercing online community. Passengers at the entrances of five

Table 1. General characteristics.

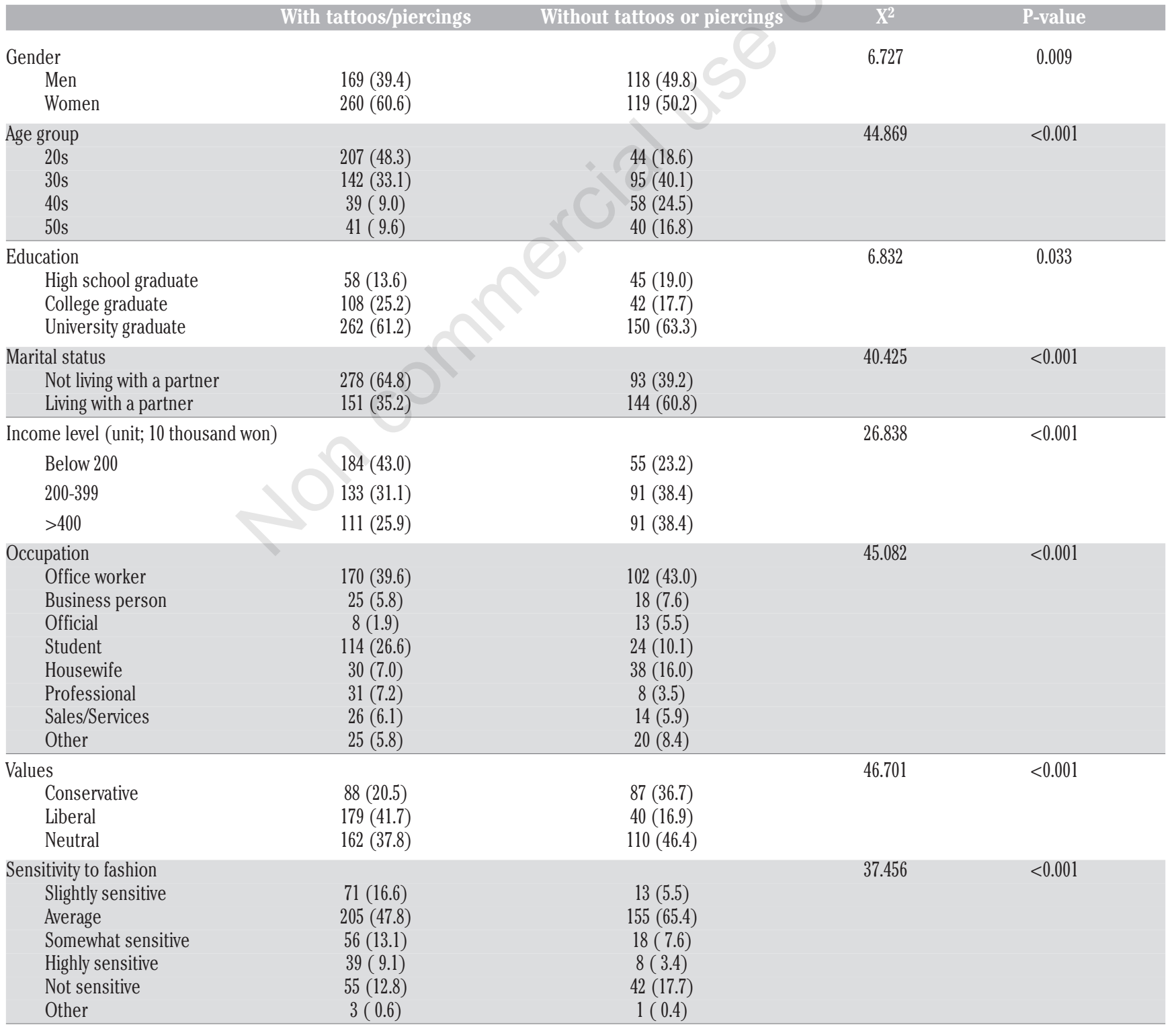


randomly selected subway stations were surveyed during the same period using the off-line survey.

A total of 690 survey questionnaires were collected, 24 of which were discarded due to invalid or missing responses, yielding a total of 666 participants in the study, comprising 429 adults with tattoos/piercings and 237 adults without tattoos or piercings. The study was approved by W University Institutional Ethics Review Board (WKIRB-201604-SB-024), and all participants provided written informed consent before data collection.

The survey questionnaires were composed of eight personal questions together with 39 questions divided into three categories: 10 questions on self-esteem, ${ }^{14} 20$ questions on the propensity for sensation seeking, ${ }^{25}$ and nine questions on the propensity for risky behaviour. ${ }^{26}$ Before surveying, four researchers, who were all experts in health and had doctoral degrees, examined the appropriateness of the questionnaires. In addition, to optimise the questionnaires, a pilot study was carried out on 30 students at the same university during 5-7 April 2016. The questionnaires were revised based on the results of the pilot study, and the main survey was conducted from 11 to 17 April 2016. Participants answered eight questions about personal characteristics: gender (male, female), age group $(20 \mathrm{~s}, 30 \mathrm{~s}, 40 \mathrm{~s}, 50 \mathrm{~s})$, education (high school graduate, college graduate, university graduate), marital status (not living with a partner, living with a partner), income level (below 200, 200-399, $\geq 400$; unit $=10$ thousand won), occupation (office worker, business person, official, student, housewife, professional, sales/services, other), self-rated values (conservative, liberal, neutral), and sensitivity to fashion (slightly sensitive, average, somewhat sensitive, highly sensitive, not sensitive, other).

\section{Measurement scales used in the survey}

Rosenberg's scale to was used to measure self-esteem. ${ }^{18}$ This scale consists of 10 items (for example: I am generally satisfied with myself), which subjects answered using a 5-point Likert scale $(1=$ strongly disagree to 5 = strongly agree $)$. Some questions contained negative meanings, and these scores were reversed as 1 (strongly agree) to 5 (strongly disagree) in the data analysis. A higher score indicated that the respondent possessed higher selfesteem. The Cronbach's $\alpha$ value of the questionnaires was 0.856 in this study. Sensation seeking was measured using the Arnett Inventory of Sensation. ${ }^{14}$ This inventory is composed of 20 items answered using a 4-point scale (for example: I prefer thrill to safety); it was designed to rate the personality trait of sensation seeking, which was assumed to contribute to risk preferences. Sensation seeking was defined as a need for novel and intense stimulation Subjects answered using a 4-point scale, where $1=$ Describes me very well, and $4=$ Doesn't describe me at all. Cronbach's $\alpha$ value of the questionnaires was 0.812 in this study.

Nine questions revised from those developed by Zuckerman were used to assess the propensity for risk behaviour. ${ }^{26}$ One of the questions in this inventory was How many times have you committed a violent act? Each question was rated as Never (1 point), 1-2 times (2 points), 3-4 times (3 points), 5-6 times (4 points), 7 or more times ( 5 points). A higher score indicated a higher number of risk behaviours. The Cronbach's $\alpha$ value for the questionnaires was 0.898 in this study.

\section{Statistical analysis}

The research data were analysed using the SPSS software program (ver. 23). The Cronbach's $\alpha$ value was calculated to test the reliability of the questionnaires. The $\chi 2$ test was used to compare the characteristics of the study and control groups. The t-test was used to determine differences in the scores. After controlling for the general characteristics, the differences in self-esteem, sensation seeking, and risk behaviour between the two groups were analysed using analysis of covariance (ANCOVA).

\section{Results}

Table 1 shows the general characteristics of each survey participant. Results indicated that $60.6 \%$ of adults with tattoos and/or piercings were women, versus $50.2 \%$ of those with no tattoos or piercings; $48.3 \%$ of participants with tattoos and/or piercings were in their 20 s, and this proportion was higher than that for any other age group. Regarding marital status, the rate of not living with a partner was higher $(64.8 \%)$ among people with tattoos and/or piercings. For income level, respondents with no tattoos or piercings had higher incomes than did those with tattoos and/or piercings. There were significant differences in occupation between the two groups. The proportions of office workers (39.6\%) and students $(26.6 \%)$ were high among subjects with tattoos and/or piercings, but the proportion of office workers $(43.0 \%)$ was yet higher among respondents with no tattoos or piercings. In terms of selfrated values, $41.7 \%$ of respondents with tattoos and/or piercings rated themselves as liberal, versus $16.9 \%$ with no tattoos or piercings. Additionally, $47.8 \%$ of respondents with tattoos and/or piercings had average sensitivity, versus $65.4 \%$ with no tattoos or piercings.

Table 2 shows differences in self-esteem, sensation seeking,

Table 2. Self-esteem, propensity for sensation seeking, and risk behaviour in adults with tattoos and/or piercings.

\begin{tabular}{|c|c|c|c|c|c|}
\hline & \multirow[t]{2}{*}{ Mean \pm SD } & \multicolumn{2}{|c|}{ Before adjustment } & \multicolumn{2}{|c|}{ Adjusted } \\
\hline & & $\mathrm{t}$ & P-value & F & P-value \\
\hline \multirow{3}{*}{$\begin{array}{l}\text { Self-esteem* } \\
\text { Adults with tattoos/piercings } \\
\text { Adults without tattoos/piercings }\end{array}$} & & 0.207 & 0.836 & 1.918 & 0.167 \\
\hline & $3.48 \pm 0.57$ & & & & \\
\hline & $3.47 \pm 0.58$ & & & & \\
\hline \multirow{3}{*}{$\begin{array}{l}\text { Propensity for sensation seeking** } \\
\text { Adults with tattoos/piercings } \\
\text { Adults without tattoos/piercings }\end{array}$} & & 10.366 & $<0.001$ & 35.489 & $<0.001$ \\
\hline & $2.59 \pm 0.32$ & & & & \\
\hline & $2.31 \pm 0.34$ & & & & \\
\hline \multirow{3}{*}{$\begin{array}{l}\text { Propensity for risk behaviour*** } \\
\text { Adults with tattoos/piercings } \\
\text { Adults without tattoos/piercings }\end{array}$} & & 4.350 & $<0.001$ & 4.191 & 0.041 \\
\hline & $1.67 \pm 0.68$ & & & & \\
\hline & $1.46 \pm 0.54$ & & & & \\
\hline
\end{tabular}

*Adjusted by gender, age group, education, marital status, income, occupation, values, sensitivity to fashion; **Adjusted by gender, age group, education, marital status, income, occupation, values, sensitivity to fashion, self-esteem ${ }^{* * *}$ Adjusted by gender, age group, education, marital status, income, occupation, values, sensitivity to fashion, self-esteem, propensity for sensation seeking. 
and risk behaviour between the two groups. After controlling for gender, age, education, marital status, income, occupation, values, and sensitivity to fashion, there was no significant difference in self-esteem between the two groups. Sensation seeking significantly differed between the two groups after controlling for the general characteristics and self-esteem, and it was significantly higher in respondents with tattoos and/or piercings $(\mathrm{M} \pm \mathrm{SD}, 2.59 \pm 0.32 v s$. $2.31 \pm 0.34)$. The propensity for risk behaviour also significantly differed between the two groups after controlling for general characteristics, self-esteem, and sensation seeking. Since self-esteem and sensation seeking were also related to risk behaviour, these two variables were used as covariates. Risk behaviour was significantly higher in respondents with tattoos and/or piercings $(\mathrm{M} \pm \mathrm{SD}$, $1.67 \pm 0.68$ vs. $1.46 \pm 0.54)$.

\section{Discussion and Conclusions}

This study investigated the general characteristics of adults with tattoos and/or piercings as well as relationships between having tattoos and/or piercings, and self-esteem and the propensity for sensation seeking and risk behaviours. Overall, the general characteristics of the respondents with tattoos and piercings differed from those with no tattoos or piercings. In addition, tattoos and piercings were not significantly associated with either lower or higher selfesteem. However, participants with tattoos and piercings differed from participants without tattoos and piercings in that they had a greater propensity for sensation seeking. This study identified relationships between tattoos and piercings and certain forms of adult behaviour and provided useful information on factors that influence people who chose to have a tattoo or piercing, information that might have a bearing on their need for public health education.

Previous studies showed that tattoos and piercings were associated with negative perceptions. Horne et al. reported perceptions associating tattoos or piercings with low social position, crime, and delinquency, resulting in many parents' not wanting to allow their children to undergo these procedures. ${ }^{27}$ Historically, a tattoo was perceived as something appropriate only for men. ${ }^{7}$ If a woman had a tattoo, she was stigmatised as a heavy drinker or as less attractive. 9,28 Over time, it became more common for other groups to have tattoos or piercings. ${ }^{7,29,30}$ In this study, respondents with tattoos and/or piercings were more likely to be women who were in their 20s, university graduates, not living with a partner, office workers, liberal, and with higher fashion sensitivity. Adams reported that young age groups of low income and low education level were more likely to have tattoos or piercings, which was consistent with the results of our study in terms of young age groups and low income having more tattoos or piercings, although in our study, university graduates were more likely to have tattoos or piercings. ${ }^{23}$ Korea has the fourth highest adult tertiary education rate among Organisation for Economic Co-operation and Development countries, ${ }^{31}$ which could explain why the respondents with tattoos or piercings in our study were more likely to have a higher education level.

High self-esteem has been viewed as an indicator of having satisfying social relationships, having achieved more, and having developed healthy behaviours. ${ }^{32}$ Furthermore, people with high self-esteem have been reported to show positive emotions, psychological adaptation, and pro-social skills. ${ }^{15}$ In this study, there was no significant relationship between tattoos and/or piercings and self-esteem, which was consistent with Carroll and Anderson. ${ }^{33}$ However, several studies reported that body cosmetic procedures were correlated with low self-esteem or negative self-concept. ${ }^{11,12}$ In contrast, studies published after 2000 reported that body cos- metic procedures were related to high self-esteem..$^{20,21}$ Hence, the relationship between self-esteem and tattoos/piercings remains controversial.

The propensity for sensation seeking has been described as the tendency to pursue diverse and intense sensations and experiences. ${ }^{26}$ Those who were attracted to sensation seeking were seeking novel and exciting experiences and sought ways to create such experiences. The search for novelty and intense experiences can appear in several areas of life $^{25}$ and can be expressed as antisocial behaviour in the context of personality or surroundings, or be channelled in a desirable direction, such as creativity. In addition, sensation seeking has been closely linked to psychological factors such as extroversion, impulsive tendencies, anti-social behaviour, unresponsive attitude, or low anxiety levels. ${ }^{26} \mathrm{~A}$ high propensity for sensation seeking was closely linked to drug abuse, alcohol consumption, smoking, and criminal acts. ${ }^{34}$ In particular, those with the highest propensity for sensation seeking were closely linked to smoking, cannabis consumption, and drug misuse, regardless of cultural differences. ${ }^{26}$ Several studies reported a stronger link between sensation seeking and body cosmetics in teens and young adults. ${ }^{13,16,21,35}$ Our study also indicated that tattoos/piercings were associated with a higher propensity for sensation seeking. In addition, Arnett reported that gambling and risky sexual behaviour were closely related to sensation seeking. ${ }^{36}$ Other types of risk behaviour are more likely when individuals have a higher tendency for sensation seeking. In previous studies, the propensity for risk behaviour has often been used to mean the same as engaging in risk-taking behaviour. Participants with tattoos and piercings displayed a higher propensity to risky sexual behaviour and drug abuse, ${ }^{17}$ moreover, adolescents with piercings were statistically significantly more likely to exhibit suicidal behaviour. Roberts et al. reported that truancy, running away from home, suicidal thoughts, suicide attempts, and drug abuse among adolescents were highly associated with piercings. ${ }^{16}$ Therefore, these studies suggest that piercings can serve as an indicator of potential risk behaviour. In addition, numerous studies have also reported that tattoos could act as an indicator of potential risk behaviour, e.g., drug use, ${ }^{32}$ alcohol consumption, ${ }^{37}$ risky sexual behaviour, ${ }^{35,38,39}$ and illegal violence. ${ }^{8,40}$

Future studies should include a wider range of socioeconomic groups, despite the fact that studies to date have produced consistent results. Since tattoos and piercings are potential factors for risky health behaviour, attention should be paid to appropriate health awareness programs. Studies on tattooing and piercing trends will be useful for determining which groups may have higher risks for unhealthy behaviours and might benefit from intervention programs, even though tattoos and piercings are not inherently unhealthy forms of self-expression. This study had several limitations: the results could not be generalised because our study populations were not sufficiently representative; moreover, this study failed to obtain detailed results on the characteristics of the participants. The cross-sectional study design precluded any inferences regarding causation. This study investigated relationships between tattoos and piercings, and self-esteem, the propensity for sensation seeking, and risk behaviour in adults. This population might exhibit risk behaviour and may, therefore, represent a target group for public health education, as the propensity for sensation seeking is more prevalent among those with tattoo/piercings, as compared to the general population. This study identified factors associated adults' choice to have tattoos and/or piercings. Thus, it provides useful information about whether adults with tattoos and piercings might be an appropriate target group for public health interventions. 
Correspondence: Hyo Young Lee, Department of Health Administration, Dongseo University, 47 Jurye-ro, Sasang-Gu, Busan 47011, South Korea. Tel.: +82.10.52614469 - Fax: +82.51.3202723.

E-mail: princesa@dongseo.ac.kr; princesa2@daum.net

Key words: sensation seeking, risk behavior, tattoo, piercing, propensity

Acknowledgements: This study was supported by Kyungil University Professor Research Grant 2016 and Dongseo University Professor Research Grant 2016.

Contributions: BKH and HYL had full access to all of the data in the study and take responsibility for the integrity of the data and the accuracy of the data analysis. Study concept and design: BKH. Acquisition of data BKH and HYL. Statistical analysis: BKH and HYL Interpretation of the results: BKH and HYL. Drafting of the manuscript: BKH and HYL. Critical revision of the manuscript for important intellectual content: BKH and HYL. Final approval of the version to be published: BKH and HYL.

Conflict of interest: the authors declare no conflict of interest.

Received for publication: 18 July 2017.

Accepted for publication: 23 October 2017.

CC Copyright B-K. Hong and H. Young Lee, 2017

Licensee PAGEPress, Italy

Journal of Public Health Research 2017;6:1107

doi:10.4081/jphr.2017.1107

This work is licensed under a Creative Commons Attribution NonCommercial 4.0 License (CC BY-NC 4.0).

\section{References}

1. Armstrong ML, Kelly L. Tattooing, body piercing, and branding are on the rise: perspectives for school nurses. J Sch Nurs 2001;17:12-23.

2. Armstrong ML, Ekmark E, Brooks B. Body piercing: promoting informed decision making. J Sch Nurs 1995;112:20-5.

3. Velliquette AM, Murray JB, Creyer EH. The tattoo renaissance: an ethnographic account of symbolic consumer behavior. Adv in Consum Res 1998;25:461-7.

4. Martin B, Dula C. More than skin deep: perceptions of, and stigma against, tattoos. Coll Stud J 2010;44:200-6.

5. Kjeldgaard D, Bengtsson A. Consuming the fashion tattoo. Consum Res 2005;32:172-7.

6. Armstrong ML, McConnell C. Tattooing in adolescents, more common than you think: the phenomenon and risks. J Sch Nurs 1994;10:26-33.

7. Braverman S. One in five U.S. adults now has a tattoo [cited in 2016 Sep 9]. Available from http://www.prnewswire.com/ news-releases/one-in-five-us-adults-now-has-a-tattoo140123523.html.

8. Roberts T, Ryan S. Tattooing and high-risk behavior in adolescents. J Pediat 2002;110:1058-63.

9. Hawkes D, Senn C, Thorn C. Factors that influence attitudes toward women with tattoos. Sex Roles 2004;50:593-604.

10. Anderson RR. Commentary: tattoos and body piercing. J Am Acad Dermatol 2006;55:422.

11. McGee R, Williams S. Does low self-esteem predict health compromising behaviors among adolescents? J Adolescence 2000;23:569-82.

12. Beer J, Beer J. Burnout and stress, depression and self-esteem of teachers. Psychol Rep 1992;71:1331-6.

13. Wohlrab S, Stahl J, Kappeler PM. Modifying the body: motivations for getting tattooed and pierced. Body Image 2007:4:87-95.

14. Rosenberg M. Society and adolescent self-image. Princeton,
NJ: Princeton University Press; 1965, p.10-100.

15. Leary MR, MacDonald G. Individual differences in selfesteem: a review and theoretical integration. New York: Guilford Press; 2003, p.401-418.

16. Roberts T, Auinger P, Ryan S. Body piercing and high-risk behavior in adolescents. J Adolesc Health 2004;34:224-9.

17. Armstrong ML, Koch JR, Saunders JC, et al. The hole picture: risks, decision making, purpose, regulations, and the future of body piercing. Clin Dermatol 2007;25:398-406.

18. Carney K, Dhalla S, Aytaman A, et al. Association of tattooing and hepatitis $\mathrm{C}$ virus infection: a multicenter case $\square$ control study. J Hepatol 2013;57:2117-23

19. Jafari S, Copes R, Baharlou S, et al. Tattooing and the risk of transmission of hepatitis C: a systematic review and meta-analysis. Int J Infect Dis 2010;14:e928-40.

20. Pajor AJ, Broniarczyk-Dyła G, Sweettalks J. Satisfaction with life, self-esteem and evaluation of mental health in people with tattoos or piercings, Psychiatr Pol 2015;49:559-73.

21. Stirn A. Prevalence of tattooing and body piercing in Germany and perception of health, mental disorders, and sensation seeking among tattooed and body-pierced individuals. J Psychosom Res 2006;60:531-4.

22. Heywood W, Smith PK, Armstrong JM, et al. Who gets tattoos? Demographic and behavioral correlates of ever being tattooed in a representative sample of men and women. Ann Epidemiol 2012;22:51-6.

23. Laumann AE, Derick AJ. Tattoos and body piercings in the United States: a national data set. J Am Acad Dermatol 2006;55:413-21.

24. Adams J. Marked difference: tattooing and its association with deviance in the United States. Deviant Behav 2009;30:266392.

25. Arnett J. Sensation seeking: a new conceptualization and a new scale. Pers Individ Dif 1994;16:289-96.

26. Zuckerman M. Behavioral expressions and biosocial bases of sensation seeking. New York: Cambridge University Press; 1994, p.10-150.

27. Horne J, Knox D, Zusman J, Zusman M. Tattoos and piercings: attitudes, behaviors, and interpretations of college students. Coll Student J 2007;41:1011-20.

28. Irwin K. Saints and sinners: elite tattoo collectors and tattooists as positive and negative deviants. Sociol Spectro 2003;23:2757.

29. Pettigrew T, Tropp L. A meta-analytic test of intergroup contact theory. J Personal Soc Psychol 2006;90:751-83.

30. Kosut M. An ironic fad: the commodification and consumption of tattoos. J Pop Cult 2006;39:1035-48.

31. OECD. Education at a glance [cited 2016 Sep 9]. Available from: https://data.oecd.org/eduatt/adult-education-level.htm.

32. Orth U, Robins RW. The development of self-esteem. Curr Dir Psychol 2014;23:381-7.

33. Carroll L, Anderson R. Body piercing, tattooing, self-esteem, and body investment in adolescent girls. J Adolesc 2002;37:627-37.

34. White HR, Labouvie EW, Bates ME. The relationship between sensation seeking and delinquency: a longitudinal analysis. J Res Crime Delinq 1985;22:197-211.

35. Drews DR, Allison CK, Probst JR. Behavioral and self-concept differences in tattooed and nontattooed college students. Psychol Rep 2000;86:475-81.

36. Arnett J. Sensation-seeking, aggressiveness, and adolescent reckless behavior. Pers Individ Dif 1996;20:693-702.

37. Silver SJ. Tattoo acquisition: a prospective longitudinal study of adolescents. Deviant Behav 2009;30:511-38. 
38. Burger TD, Finkel D. Relationships between body modifications and very high risk behaviors in a college population. Coll Student J 2002;36:203-13.

39. Koch JR, Roberts AE, Armstrong ML, Owen D. College students, tattoos, and sexual activity. Psychol Rep 2005;97:88790 .
40. Deschesnes M, Fines P, Demers S. Are tattooing and body piercing indicators of risk-taking behaviors among high school students? J Adolesc 2006;29:379-93. 